\title{
ERGONOMICS IN THE PIANO ACCORDION KEYBOARD
}

\author{
Nikolay Kravtsov
}

Saint Petersburg State Institute of Culture, 2, Dvortsovaya nab. (embankment), Saint Petersburg, 191186, Russian Federation

kravtsov@accordionkravtsov.ru

\begin{abstract}
The article identifies ways to improve the organ-piano keyboard borrowed into the accordion according to the ergonomic criteria of the "man-machine" system. The corresponding keyboard transformations are shown in order to expand the information channels to achieve the criteria of the existing paradigm and improve the artistic and expressive conditions for the implementation of articulation algorithms in sound extraction. After creating the variety of the organpiano keyboard - the keyboard of the Kravtsov system - their genetic community in preserving the musical heritage of past eras and matching modern demands of the accordion culture is indicated.
\end{abstract}

Keywords: Accordion; Organ-piano Keyboard; Ergonomics;

Systems; Game Organization; Functioning; Human-Machine

\section{ЭРГОНОМИКА В ОРГАННО-ФОРТЕПИАННОЙ KАABИАTУPE AKKOPAEOHA}

\author{
Николай Кравцов \\ Санкт-Петербургский государственный институт культуры, Аворцовая \\ наб., А. 2, Санкт-Петербург, 191186, Россия
}

\begin{abstract}
Резюме: В статье выявлены пути усовершенствования заимствованной в аккорАеон органно-фрортепианной клавиатуры согАасно эргономическим критериям системы «человек-машина». Показаны соответствующие преобразования клавиатуры с целью расширения инорормационных каналов Аля Аостижения критериев существующей парадигмы и улучшения художественновыразительных условий реализации артикуляционных алгоритмов в звукоизвлечении. После созАания разновиАности органнофортепианной клавиатуры - клавиатуры системы Кравцова обозначена их генетическая общность в сохранении музыкального наследия прошлых эпох и соответствия современным запросам аккорАеонной культуры.
\end{abstract}

КАючевые слова: Аккорлеон, органно-фрортепианная

к^авиатура, эргономика, системы, организация игры,

функционирование, человек-машина 
Клавиатура, как устройство передачи инорормации от исполнителя к звукообразующему телу клавишного музыкального инструмента, в своем развитии прослеживает конструктивные преобразовании во взаимосвязи с переменчивостью научных и музыкально-эстетических парадигм. В холе эволюции хроматических к^авиатур аккорАеона постоянно трансорормировались звуковые и акустические свойства инструмента. Заимствование органнофортепианной клавиатуры (Аалее ОФК) в конструкцию аккорАеона прелполагало, опираясь на сохранение акалемического наслелия к^авишных инструментов, созАать оригинальную музыку с новым пониманием и подходом в композиторском творчестве. ОАнако, эту илею в рамках ОФК опереАили, созАанные оригинальные сочинения А^я Аругих типов и разновиАностей систем клавиатур аккордеона хроматических трёхрядных. Размещение в рядах $~$ постоянным интервалом малой терции клавиш-кнопок на трёх рядах уменьшило на $39 \%$ расстояние межАу клавишами октавы. Фактура с широко разнесёнными голосами, пассажи из Авойных нот, насыщение текста необычными приёмами звукоизвлечения и расширение диапазона на той же площали клавиатурного щита всё это привлек^о творческое внимание композиторов К созАанию оригинальных сочинений, отАичающихся от музыки Аля Аругих клавишных инструментов. В результате были созАаны сочинения, которые невозможно исполнить на ОФК без изменений авторского текста.

По эргономическим функциям системы «человек-машина» ( $а$ aлее СЧМ) создалась ситуация неизбежного изменения творческой паралигмы (возвращение инорормации по СЧМ от «машины к человеку», гАе исполнитель сам вносит преобразования в программу устройства) (Zinchenko, 1974). Художественно-выразительные свойства ОФК («машины») не обеспечивали необхолимую алекватность в реализации творческих проектов и их раскрытие в субъективном исполнительском искусстве. Основная задача, стоящая переА эргономическим преобразованием продукта мировой музыкальной культуры - ОФК, необходимость перенести позитивные функциональные свойства, несомые компактными трёхрянными клавиатурами, в её 
информационное поле. Отметим позитивное в функционировании трёхрядных систем клавиатур: возможность исполнить широко разнесённые голоса в многоголосных фоктурах и интервалах, например, в две октавы - квинтАецимы; увеличение количества унифоицированных аппликатур для гамм, аккорАов и арпеджио, что упрощает процессы игры и обучения; значительное расширение Аиапазона инструмента. Эти свойства трёхрядных клавиатур внесли переосмысления в аккорАеонную культуру и в контуры обновлённой парадигмы. Вместе с тем, недостатком настоящих систем яви^ось то. что клавиатуры не сохранили традиционную позиционную и систематическую аппликатуру пальцев и топографию их размещения как у ОФК. Этот факт прерывает существовавшую ранее преемственность и взаимосвязь межАу кАавишными инструментами прошлого и их специфиическими алгоритмами. В холе молернизации ОФК («машины») наАо было созАать эргономические обоснованные алаптивные условия, при которых исполнитель смог бы эфрорективно реализовать полученный ранее привычный опыт организации игры (фриг. 1) (Kravtsov, 2012: p. 146).

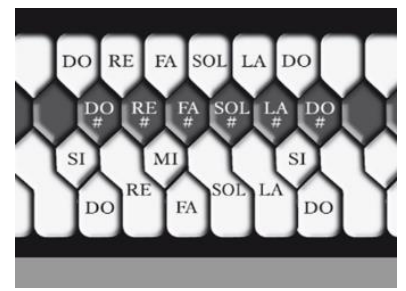

\section{Фиг.1. Модернизированная Кравцовым ОФК с улучшенными эргономическими элементами системы}

Как виАно на схеме, сжатие площали октавы осуществлено путём АиквиАации просветов межАу чёрными клавишами ОФК. Аиквидированные просветы - нефункционирующие игровые площалки белых клавиш никула не исчезли, а стали инорормационно активизированными, образовав условно говоря Аополнительный (вспомогательный) ряА основных тонов. В результате траАиционная клавиатура получила «сжатие» октавы на 30\% (Kravtsov, 2004: р. 24). Это 
визуально хорошо илмюстрировано на фоиг.2 1 и фоиг. 3, гле, при олинаковой растяжке пальцев, на КСК прожимаются кАавиши

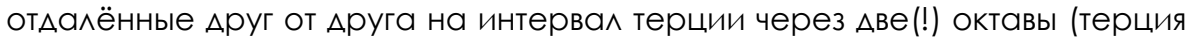
через квинтАециму).

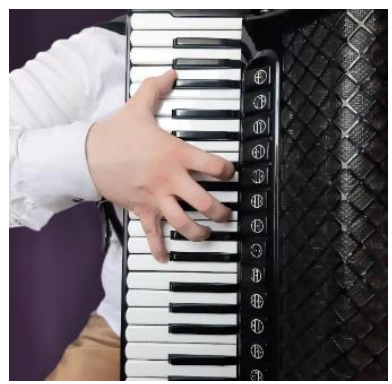

Фиг. 2. Растяжка на ОФК

\begin{abstract}
Составляет ИнтерваА "АУОАецимы»
\end{abstract} межАу прожатыми клавишами

Не выходя за рамки системы ОФК, олНим целевым

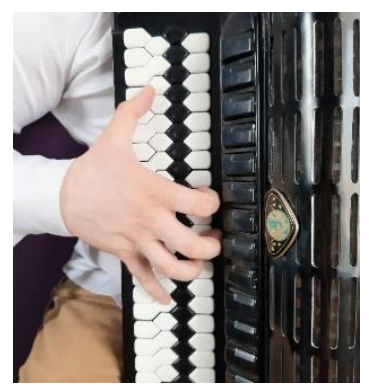

Фиг. 3. Растяжка на КСК

\section{составляет интервал Ікварта}

через Аве октавы" межАу прожатыми кАавишами преобразованием, улалось уровнять информационные возможности исполнителя на уровне парадигмы трёхрялных клавиатур. Так увеличился Аиапазон ОФК $А$ параметров трёхрялных клавиатур. Среди художественно-выразительных средств, ранее неАоступных, стало возможным воспроизводить пятиголосные аккорАы и их арпеджио (фиц.4) (Kravtsov, 2012: р. 34), исполнение интервалов с широко разнесёнными голосами в гаммообразном исполнении от малой ноны Ао КвинтАецимы (Kravtsov, 2012: pp. 141-144).

\footnotetext{
1 Злесь и далее фрото выполнены автором.
} 
3) в пятиголосном изложении:
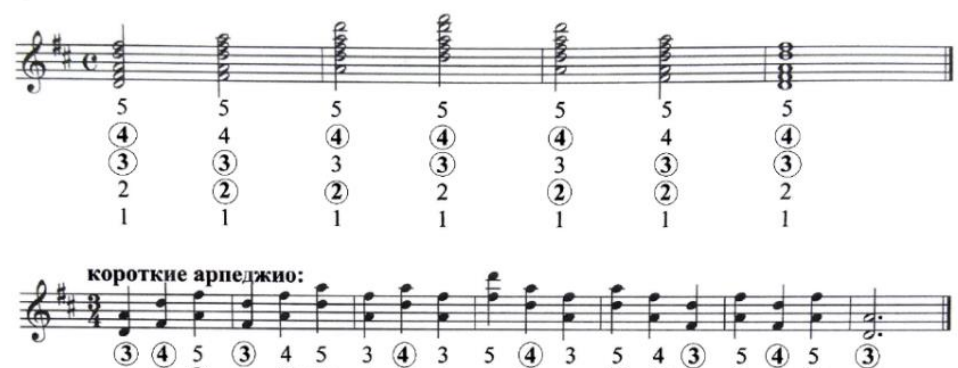

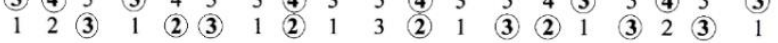

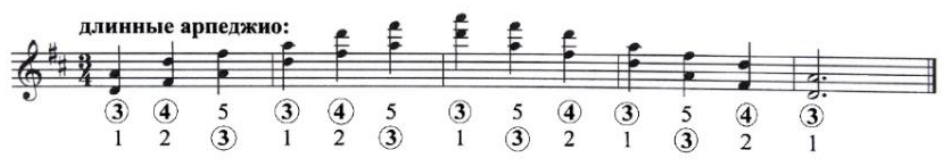

Фиг. 4. Аппликатура тонического аккораа Ре мажора в пятиголосном изложении и его арпеАжио

Упростилась игра пассажей, состоящих из Авойных нот - терций, секст, октав и Аругих интервалов (Фиг. 5) (Kravtsov, 2012: р. 32).

\section{Октавы}

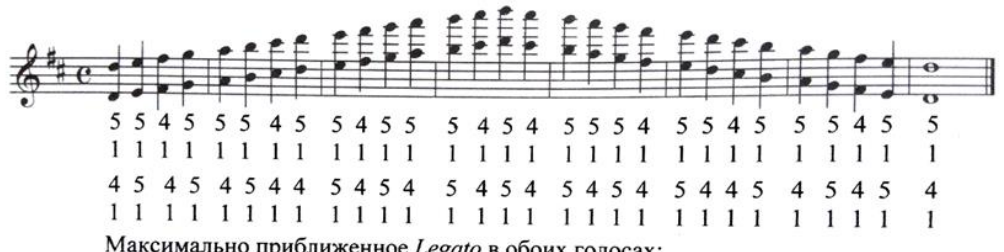

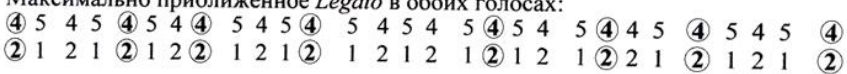

Фиг. 5. Аппиикатура гаммы октавами Ре мажор

Преобразования в условиях заимствования в аккорАеон ОФК созАали её разновиАность, которая получила название клавиатура системы Кравцова (Аальше КСК) и была защищена авторским свидетельством (Kravtsov, 1980) и ряАом патентов (ориг. 6.). 


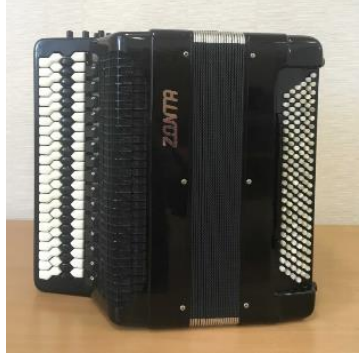

Фиг. 6. Концертная молель аккорАеона ZONTA С РазНОвИАНОСтью ОФК - СИСТеМवМИ Кравцова в правой (Аиапазон от "^я» большой АО «ми-бемолы четвёртой октавы) и мевой готово-выборной к^авиатурах.

В отличие от трёхрялных клавиатур, генетическая взаимосвязь системы ОФК с её разновиАностью КСК обеспечила сохранение иАентичности позиционной и систематической (Zimin, 1968: pp. 46-51) аппликатур, с олинаковой топографией размещения пальцев внутри позиции. Ниже приводится аппликатура хроматической гаммы малыми терциями великих пианистов прошлого, которая сохраняет их творческие илеи в условиях фрункционирования КСК (фриг. 7) (Zinchenko, 1974: pр. 132133).
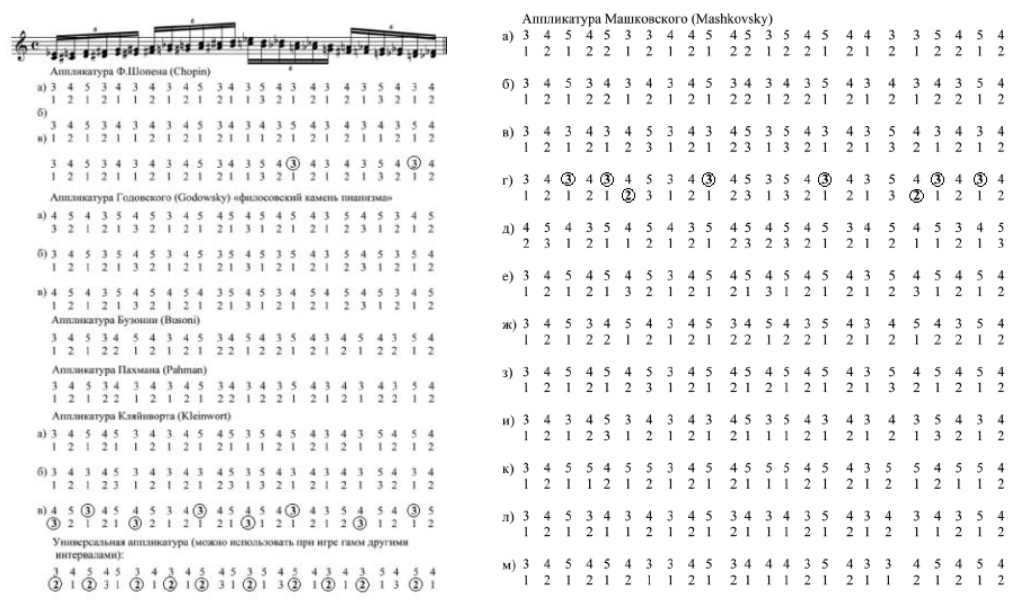

Фиг.7. Аппликатура хроматической гаммы малыми терциями

\section{выАающихся пианистов прошлого}

Общность позиционных топографрии систем ОФК и КСК упрощает инорормационный процесс, сокращает время алаптации Аля Аостижения параметров парадигмы трёхрялных клавиатур и преумножают фрункциональные возможности в созАании творческих 
проектов. В расширении инорормационных каналов от системы «исполнитель-машина» необходимо было воспользоваться критической ситуацией и изыскать возможность Аополнительно расширить границы паралигмы. Это связано с тем, что музыка весьма консервативная среда А^я нововвеАений и поводов А^я их появления в ближайшее время может и не появиться. Особенно важно, что нововведения связаны С акустическими параметрами инструмента. Важным моментом при заимствовании ОФК в конструкцию аккорАеона, на который сразу не обратили внимание, является тот оракт, что её элементы не алаптировались к его особенностям звукообразования и звукоизвлечения. Именно они, при определённых условиях, Аолжны были способствовать качеству и скорости Аостижения конечного звена алгоритма в организации артикуляционного поля инструмента.

Звукоизвлечение на аккордеоне обеспечивается воздушным потоком, направленным на язычок (Imkhanitskiy, 1997), (Corto, 1966), (Helmholtz, 1875), (Egorov, 1980), (Lips, 2007), (Zuo Jian, 2013). Авижение возАушного потока образуется Авумя Аействиями играющего - нажатием к^авиш клавиатуры как устройства и Авижением меха. Временное взаимодействие этих элементов в сочетании с вариативной скоростью, организуемой исполнителем, составляет комплекс компонентов звукоизвлечения. Особенность этой молели «машины» состоит в том, что ^юбое отпускание клавиши прекращает подачу воздушного потока на звучащий язычок и его колебания немеАленно прекращаются. Если правая педаль рояля подАерживает звук отпущенной клавиши или струна, как звучащее тело, продолжает остаточные колебания, то язычок, способен моментально прекратить колебания. Обычно штрих ^егато межАу Авумя аккорАами выполнить без скольжения пальцев по клавишам невозможно. В зависимости от этой специфики кАавиатура аккорАеона Аолжна преобразовываться в соответствии с основами эргономических рекоменАаций по улучшению условий функционирования в холе реализации конечных целей. Известные аккорлеонные фоирмы начали приспосабливать КАавиши ОФК к особенностям звучания инструмента.

Соелинение аккорловых голосов было улучшено путём вальцевания рёбер белых клавиш с большим ралиусом скругления, что 


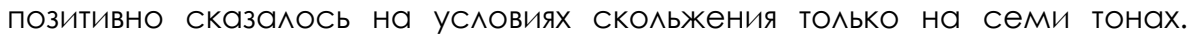
ГАубокому скруглению подверглись внешние рёбра белых клавиш (У края грифра), чтобы хоть как-то улучшить условия «растяжки» межАу пальцами, гАе участвует большой палец. ИзготовитеАи ОФК старались также закруглить концы чёрных клавиш Аля удобства скольжения пальцев с белого ряла на чёрный. У трёхголосных систем этот неАостаток присутствует в иной системной форме. Ступенчатое расположение рялов кнопок несёт те же неАостатки в фрункционировании клавиатуры, чтО И у ОФК.

С эргономической точки зрения это никак нельзя назвать полноценным. Были попЫтки сгАаАить этот неАОстаток заменить форму клавиши на квалратную, но она не прижилась так как её углы ухудшали условия игры и имели контактные рёбра квалратов только в своём ряАу. Реальным решением оказалось уменьшение высоты размещения рялов относительно Аруг Аруга, но системно улучшить условия скольжения не улалось. Таким образом, разновысотное размещение клавиш на к^авиатурном щите у ОФК и трёхряАных кАавиатур не позво^я^о в полной мере улучшить художественно-выразительные срелства артикуляции, которыми несомненно облаАает инструмент.

Чтобы АиквиАировать неАостатки звукоизвлечения вызываемые неровностями размещения рядов клавиш, в преАложенной КСК ряАы КАавиш тонов и полутонов ^ежат в оАной п^оскости. Ни КАавиши ОФК, Ни кнопки трёхрядных клавиатур не могут обеспечить реализацию проекта по улучшению алгоритма, например, артикуляционного штриха ^егато (ит. legato). КАавиши КСК выполнены в форме многогранника, гАе сосеАствующие вальцованные рёбра клавиш позволяют улобно скользить пальцами уже с пятью сосеАними клавишами (Kravtsov, 2004: р. 26). В привеАённом отрывке «Провожание» из сюиты Аля баяна «Узоры ^уговые» Шендерёва Г. Г. в транскрипции Аля баяна выполнить качественное ^егато сложно, а моментами невозможно (Фиг. 8). Трёхрянная система ступенчатой клавиатуры баяна не в состоянии полноценно обеспечить артикуляционные приёмы скольжения. В то время как, благоларя фрорме кАавиш, КСК успешно справляется с этой важной исполнительской залачей. В примере приведён вариант аппликатуры, обеспечивающей 
слитное звучание во всех голосах фрактуры при помощи «скользящей» аппликатуры.
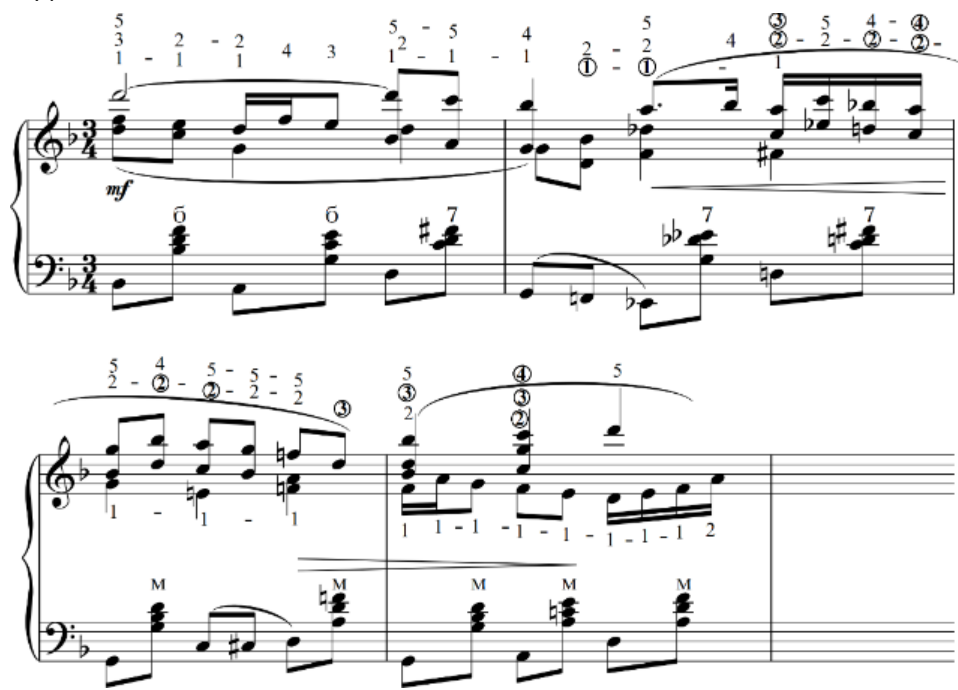

Фиг. 8. Скользящая аппликатура, обеспечивающая штрих легато в части «Провожание» (17-20 такты) из сюиты А^я баяна «Узоры ^уговые»

\section{Г.Г.ШенАерёва}

Уникальные возможности игры на кАавишах-Кнопках появАяются благодаря большим просветам (шпациям) межАу ними.

Этим элементом уравниваются условия игры Аля маленьких и больших пальцев, так как размеры шпаций расширяют зону межАу сосеАними Кнопками Аля прохожАения крупных ногтевых фраланг. Устройство позволяет также сократить шаг кАавиши $\Delta о 16$ мМ, что существенно влияет на эргономику Авижения, возможное увеличение Аиапазона инструмента и обогащение художественно-эстетическими каналами паралигмы инорормационно-исполнительскими иАеями.

Это изящное решение в строении компактных трёхрядных клавиатур сохранено в КСК благодаря созАанию выпуклости на поверхности многогранника (фриг. 9). 


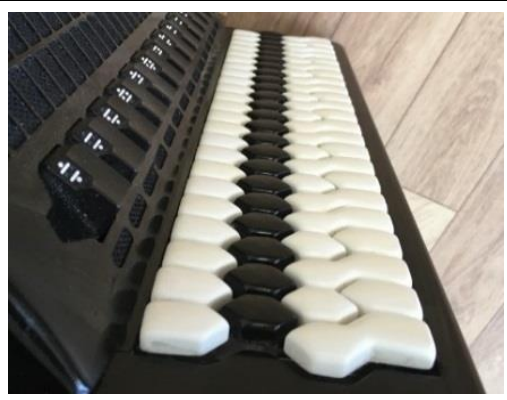

Фиг.9. Выпук^ая форма клавиш КСК

Наконец, модернизация ОФК показала серьёзное расширение инорормативной базы унификации типовых аппликатур и их топографий (Kravtsov, 1982). В исслеАОвании показаны иАентичность позиции КСК с ОФК, их топографиии размещения пальцев внутри привычных А^я ОФК позиций. Укажем Аве из них -топографоию размещения пальцев в мажорных аккордах (схема 2, фрото 5 и 6) и миатонических гаммах (схема 3). Унифрицированной позицией и неизменной топографрией размещения пальцев внутри неё можно исполнить 9(!) из 12-ти тонических аккорАов мажорных гамм - Ао, Соль, Ре, Ая, Ми, Фа, Ми-бемоль, Ая-бемоль, Ребемо^ь (фоиг.10).

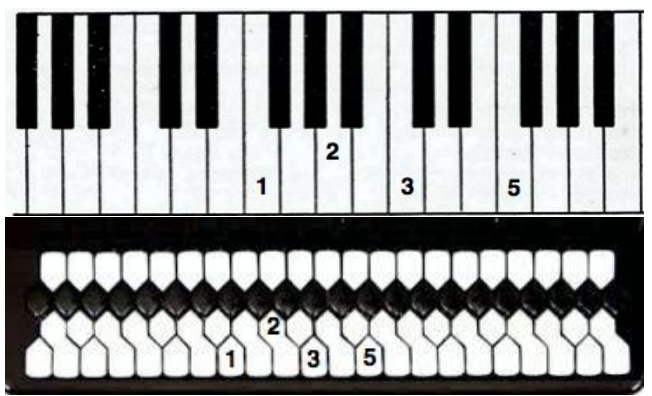

Фиг. 10. Унифицированная топография аккорАовых позиций в 9-ти мажорных тональностях - Ао, Соль, Ре, Ая, Ми, Фа, Ми-бемоль, Аябемоль, Ре-бемомь на КСК и её прототип у ОФК

В реальности топография преАставлена на фиг. 11 и 12 . Читателю не представиться труда проследить на КСК по ориг. 13 или ориг 12 илентичные топографиии размещения пальцев у девяти аккорАов. 3Аесь уместно заметить, что аппликатура всех взятых на ОФК мажорных 
аккорАов будет одинаковой, но с разной топографиией внутри позиции. Ааже похожие по топографоии аккорды от нот Ре и Ая имеют различную топографию из-за отличающихся расстояний межАу кАавишами «ре»«фра-лиез» и «ля-«Ао-Аиез». Сохраняется на ОФК и аппликатура аккорАа от ноты «си-бемолы», но это уже совсем Аругая топографрия, требующая от играющего орормирования особого навыка.

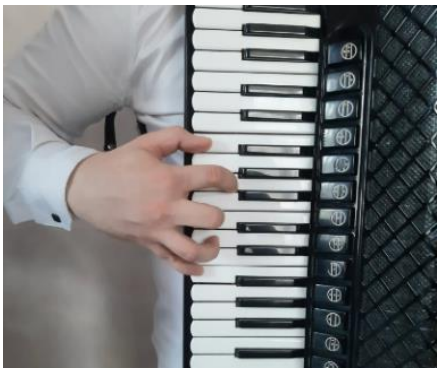

Фиг. 11. Мажорный аккорА от ноты Фа на ОФК

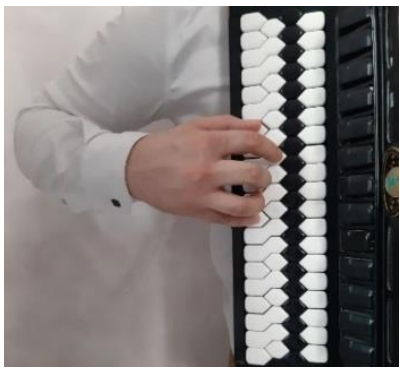

Фиг. 12. Мажорный аккорА от ноты Фа на KCK

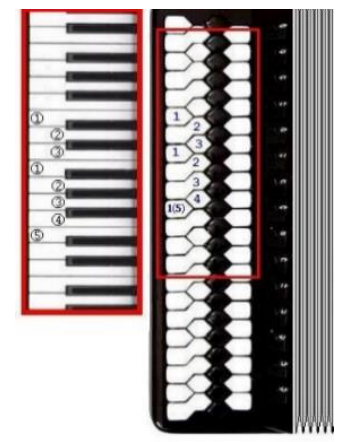

Фиг. 13. Унифицированная топография размещения пальцев в мажорных гаммах - Ао, Си, Си-бемоль на ОФК и КСК

К^авиатура как устройство в понятии эргономической системы «человек-машина» (СЧМ) в отличие от Аругих технических систем характеризуется рядом вносимых в неё свойствами, присущими исполнительской Аеятельности человека.

Это универсализм, алаптивность, помехоустойчивость и резервирование (Zinchenko, 1974: р. 22). Универсализм проявляется в том, что исполнитель (аккорАеонист) может использовать по-новому свойства

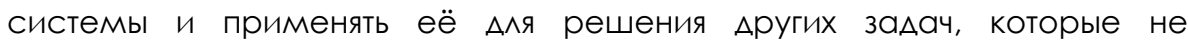


планировались при проектировании. Так в КСК при сжатии площаАи октавы, вытесненные участки белых клавиш как элемент обеспечили широкий круг униорицированных аппликатур базовых технических орормул, которые не предусматривались ранее. Стали возможными новые виАы А^я КАавишных инструментов гАиссанАо.

ААаптивность полразумевает расширение миапазона приспособляемости системы к меняющимся условиями её фрункционирования, которая осуществлялась Авумя путями. ОАин путь насыщен изменениями алгоритмов системы, Аругой - изменениями характеристик системы по отношению к входным сигналам. Настоящее свойство КСК бы^о обеспечено изменением форм клавиш ОФК в многогранник и размещение клавиш 12-ти ступеней хроматического звукоряда на одном уровне. Помехоустойчивость осуществляется благоларя существующему у человека информационных каналов с разными психолого-физиологическими механизмами (зрение, осязание и т. А.). Они позволяют использование Аублирующего восприятия Аля повышения помехоустойчивости и помехозащищённости систем. У ОФК и КСК этому служат формы клавиш и их окраска в чёрные и белые цвета. Резервирование у устойчивого исполнителя возможно в широких прелелах и связано с особенностью реализацией резервированной у него компенсации непредусмотренных отказов, Аействия которых заранее неизвестны.

Хорошо обученный, эмоционально устойчивый аккорАеонист контролирует исполнительский процесс и ликвиАирует сбои в работе с системой, повышая тем самым уровень налёжности СЧМ. У ОФК И КСК общность позиционной топографрии во многом обеспечивает эту HaАёжнОСть.

Таким образом, органно-орортепианная клавиатура, заимствованная в аккордеон, остается базовой в музыкальноэстетическом воспитании, традиционных и массовых жанрах музыкальной культуры (фролк, Ажаз, рок, кроссовер и т. п.). Улучшение её эргономических свойств привело к созАанию и внеАрению в практику аккорАеонного искусства её разновиАности - клавиатуры системы Кравцова, которая привнесла новые оттенки художественно- 


эстетическим элементам паралигмы, зародившейся в

функционировании трёхрядных типов кАавиатур.

С клавиатурой системы Кравцова линия заимствованной органно-фортепианной клавиатуры в конструкцию аккорАеонов с хроматическим строем обрела эволюционную органологическую законченность. Аанная система облалает необходимыми параметрами, которые отвечают запросам современной музыки, и её оригинальным композициям Аля типов трёхрядных кАавиатур аккорлеона (в Российской Фелерации баяна), исполнительству и решению музыкальнопелагогических залач.

\section{AИTEPATYPA / REFERENCES}

Corto, A. (1966). Rational principles of piano technique / Ed. and per. with French and comments. Ya.Milstein, $-M$ : Publishing house. Music, 1966. -108 p // [Корто A, Рациональные принципы фоортепианной техники/ РеА. и пер. с фрранц. и коммент. Я.Мильштейна, - М.: ИзА. Музыка, 1966. - 108 с.]

Egorov, B. M. (1980). Means of articulation and strokes on the button accordion. Questions of professional education of the accordion player. Collection of works, issue 48. Resp. editor BM Egorov, - M., 1980, -160 р., рр. 86-103 // [Егоров Б. М. Средства артикуляции и штрихи на баяне. // Вопросы продрессионального воспитания баяниста. Сборник трудов, вып.48. Отв. реАактор Б.М.Егоров, -М., 1980, - 160 C., C 86-103]

Helmholtz, G. (1875). The doctrine of auditory sensations as a physiological basis for the theory of music. - SPb., 1875. -594р. // [Гельмгольц Г. Учение о слуховых ощущениях как фризиологическая основа д^я теории музыки. - СПб., 1875. 594 c.]

Imkhanitskiy, M. I. (1997). New about articulation and strokes on the button accordion / MI Imkhanitsky. -M .: Publishing house of the Russian Academy of Music im. Gnesin, 1997. - 44 р. // [Имханицкий М.И. Новое об артикуляции и штрихах на баяне / М. И. Имханицкий. - М.: ИзА-во РАМ им. Гнесиных, 1997. - 44 с.]

Kravtsov, N. A. (1980). 12 Keyboard for the musical instrument Kravtsov (in Russian) In: Bulletin No. 35. USSR. 765866 USSR. MKI3 G10C3. // [A. c. 765866 CССР. МКИ3 G10C3/12 КАавиатура А^я музыкального инструмента Кравцова / Н. А. Кравцов. — № 2507859/2812; заявлено 14.07.77; опубликовано 23.09.80. Бюл^етень № 35. 2 с.: и^.] 
Kravtsov, N. A. (1982). Improvement of the organ-piano keyboard of the accordion and urgent problems of harmonious-button accordion performance: dis. Cand. art history: 17.00.02 / Kravtsov Nikolay Alexandrovich; [LGITMiK]. —L., 1982. —223 p. — Bibliography: pр. 216-223. // [Кравцов Н. А. Усовершенствование органнофортепианной клавиатуры аккорлеона и назревшие проблемы гармоннобаянного исполнительства: Аис. канА. искусствоведения: 17.00 .02 / Кравцов Николай Александрович; [АГИТМиК]. - ^., 1982. - 223 с. - Библиографрия: с. 216-223.]

Kravtsov, N. A. (2004). Accordion of the XXI century / N. A. Kravtsov. -SPb. : Publishing house "MCT", Russia, 2004. -124 р. // [Кравцов Н. А. Аккордеон XXI века / Н. А. Кравцов. - СПб. : ИзАательство «МСТ», 2004. - 124 С.

Kravtsov, N. A. (2012). Tables of fingering scales, chords and arpeggios for a readymade accordion: textbook. allowance / N. A. Kravtsov; Ministry of Culture of the Russian Federation, St. Petersburg State University of Culture and Arts, Faculty of Arts, dept. bunk bed tools; notographer. works by S. Algin. -SPb. : Ed. SPbGUKI, 2012. 148р. // [Кравцов Н. А. Таблицы аппликатур гамм, аккорлов и арпеджио Аля готово-выборного аккордеона: учеб. пособие / Н. А. Кравцов; Министерство культуры РФ, Санкт-Петербургский государственный университет культуры и искусств, фракультет искусств, каф. нар. инструментов; нотографр. работы С. ААьгина. - СПб. : ИзА. СПбГУКИ, 2012. - 148с.]

Lips, F. (2007). On the art of button accordion transcription: Theory and practice. $-M$.: Music, - 2007. -136 s., Notes // [^ипс Ф. Об искусстве баянной транскрипции: Теория и практика. - М.: Музыка, - 2007. - 136с., нот]

Zimin, P. N. (1968). History of the piano and its predecessors. - M: Muzyka, 1968. - 215 p. // [Зимин П. Н. История фрортепьяно и его предшественников. - М.: Музыка, 1968. 215 c.]

Zinchenko, V. P. (ed.) (1974). Introduction to ergonomics (in Russian), Publisher: Soviet radio, Moscow, 1974, р. 352 // [Введение в эргономику. Пол редакцией В.П.Зинченко. М.: ИзА. Советское ралио, 1974. - 352 с.]

Zuo Jian (2013). Conditions for realizing the artistic, creative and pedagogical potential of the innovative ergonomic properties of accordion keyboards: author. dis. Cand. ped. Sciences: 13.00.02 / Tso Dzyan; [St. Petersburg. state University of Culture and Arts]. - SPb., 2013. -19 р. // [Цзо Цзянь Условия реализации художественнотворческого и педагогического потенциала инновационных эргономических свойств аккорАеонных клавиатур: автореф. Аис. канА. пеА. наук: 13.00 .02 / Цзо Азянь; [С.-Петерб. гос. ун-т культуры и искусств]. - СПб., 2013. - 19 с.] 


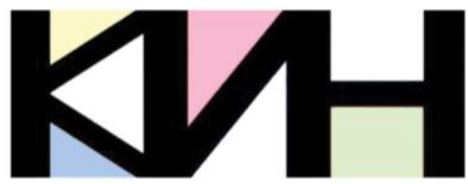

КУАТУРНО-ИСТОРИЧЕСКО НАСАЕАСТВО:

ОПАЗВАНЕ, ПРЕАСТАВЯНЕ, АИГИТААИЗАЦИЯ

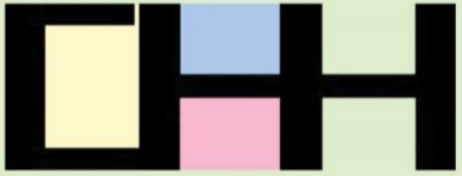

CULTURAL AND HISTORICAL HERITAGE: PRESERVATION, PRESENTATION, DIGITIZATION
Материалите в сборника са обект на авторско право. Разрешава се безвъзмезАното ползване на техни електронни/ хартиени копия само за лична употреба или обучение, при пь^но цитиране на текущата страница и слеА писмена декларация от цитиращия за мипса на търговски намерения.

(с) Авторски колектив, 2020

Техническо реАактори: Калина Сотирова-Вълкова Николай Ноев Паска^ Пиперков

\section{Editors}

Petko St. Petkov

Galina Bogdanova

This work is subject to copyright. Open and free of charge use of digital/hard copies of publications is granted only for personal or educational use, with full citation of the current page, and after written declaration of the quoting side for notcommercial Intention.

(C) Authors` Group, 2020

Technical editors:

Kalina Sotirova-Valkova

Nikolay Noev

Paskal Piperkov

НАЦИА регистрационен № 1209

Научна пореАица: том 6, брой 2 (9)/2020

Science series: vol. 6 , issue $2(9) / 2020$

NCID Registry No. 1209

www.math.bas.bg/vt/kin

ISSN: 2367-8038 